\title{
Quadricuspid Aortic Valve: Report of a Case Combined with Moderate Ascending Aortic Dilatation
}

\section{Case Description}

A 70-year-old female patient was suffering from progressive shortness of breath due to severe aortic regurgitation (AR), followed approximately two years prior to surgery. On physical examination, a murmur with a 3/6 intensity was present and best heard at apex. No history of serious previous illness had been recorded.

As expected in QAV the principal investigating method was transthoracic echocardiography (TTE), extensively supplemented with additional diagnostic tools. These included transesophageal echocardiography (TEE) ( Fig. 1), multi-slice computed tomography (MSCT) ( Fig. 2 and $\triangleright$ Fig. $\mathbf{3}$ ), and coronary angiography (CA).

\section{Discussion}

QAV is a rare congenital heart disease with an incidence of $0.0059-0.0065 \%$ for patients undergoing TTE. They represent only 0.05-1\% for those receiving AVR (Tsang MYC et al., Circulation. 2016 Jan 19;133(3): 312-9). Most QAVs progress to AR. The timing and type of surgical intervention (repair vs. replacement) should be weighed according to clinical condition, objective diagnostic findings, and the patient's age. Aortic valve replacement in patients at an age and in a condition similar to our case is a recommended method of treatment, with the use of biological or mechanical valve prosthesis according to concomitant diseases and patient preferences. TTE and TEE in this symptomatic patient verified regurgitant QAV with its progressive insufficiency, dilatation of the heart chambers, and wall thickening. QAV was classified as type E by Hurwitz and Roberts classification and as type II by Nakamura classification (Hurwitz LE \& Roberts WC, The American Journal of Cardiology, 1973; 31(5), 623626; Nakamura Y et al. Jpn J Thorac Cardiovasc Surg (2001); 49: 714). Additionally, no other anatomical disorders but mild dilata-

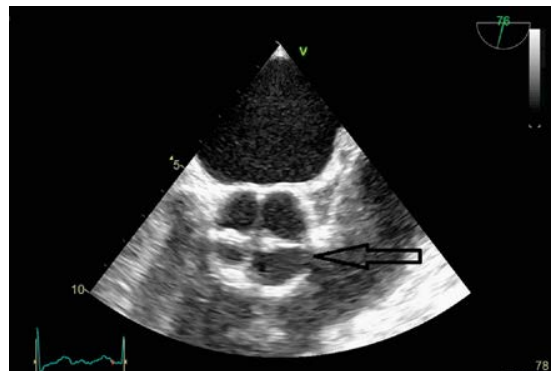

- Fig. 1 QAV in preoperative transesophageal echocardiography (TEE). Arrow is pointing to LCC and ostium of LM coronary artery.

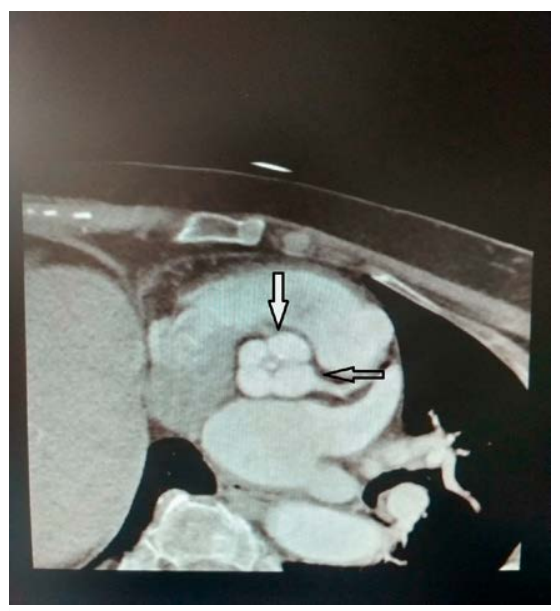

- Fig. 2 QAV in preoperative multi-slice computed tomography (MSCT). The position of the origins of the coronary arteries classified this QAV as type II by Nakamura classification. (hollow arrow: LCC and ostium of LM coronary artery; white arrow: RCC and ostium of RCA).

tion of the ascending aorta was confirmed by MSCT. CA, as part of routine preoperative screening for possible stenoses of the coronary arteries, was also used in this patient for verification of their typical origin and course. Neither stenoses nor anatomical anomalies of the coronary arteries were detected. As indicated by the patient's clinical status, diagnostic findings, the patient's age, and her preference, aortic valve replacement (AVR) by bioprosthesis was performed. The mildly dilated ascending aorta was not addressed. Surgery was uneventful, and she was released home on the fifth postoperative day. A good postoperative result in a follow-up four months after the intervention was seen ( $>$ Fig. 4).

Conflict of Interest

The authors declare that they have no conflict of interest.

Authors

Boris Zrnic ${ }^{1}$, Slavica Kovačíc ${ }^{2}$, Teodora Zaninovic Jurjevic ${ }^{3}$, Marin Ostric ${ }^{1}$

\section{Affiliations}

1 Department of Cardiothoracic Surgery, Clinical Hospital Centre Rijeka, Rijeka, Croatia

2 Department of Radiology, Clinical Hospital Centre Rijeka, Rijeka, Croatia

3 Department of Cardiovascular Diseases, Clinical Hospital Centre Rijeka, Rijeka, Croatia

received 21.12.2020

accepted after revision

25.05.2021

\section{Correspondence}

\section{Boris Zrnic}

Cardiothoracic surgery

KBC Rijeka

T. Strizica 3

51000 Rijeka

Croatia

Tel .: + 38591511 2844, Fax : + 38551218861

boriszrnic@yahoo.co.uk 


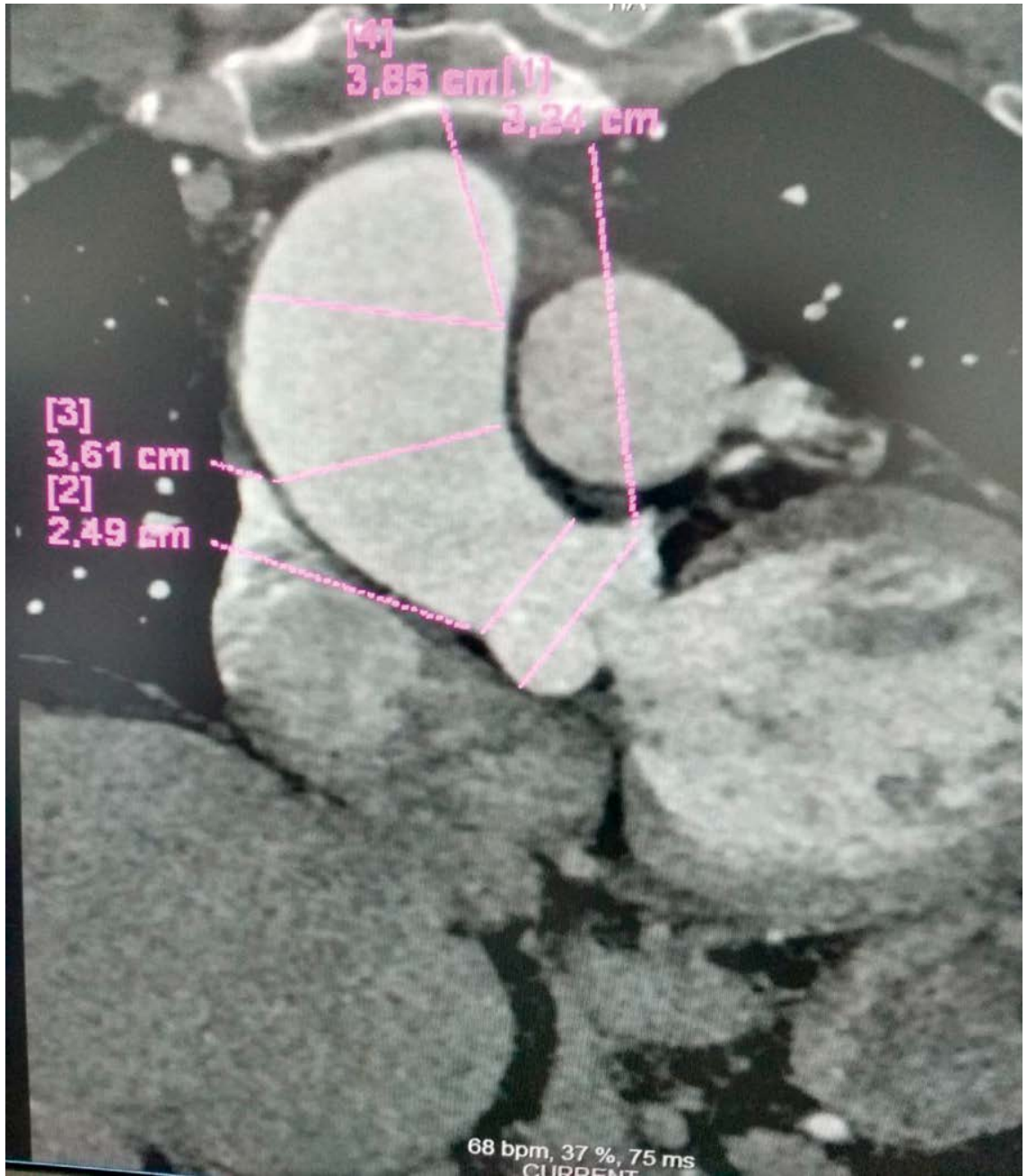

- Fig. 3 MSCT aortography in QAV revealing moderate ascending aortic dilatation (measurements).

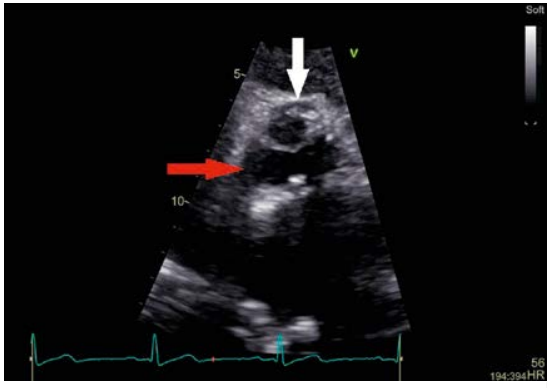

Fig. 4 Postoperative transthoracic echocardiography (TTE) of AV bioprosthesis. (red arrow: bioprosthetic LCC; white arrow: bioprosthetic RCC).

Bibliography

Ultrasound Int Open 2021; 7: E46-E47

DOI 10.1055/a-1543-9673

ISSN 2199-7152

(c) 2021. The Author(s).

This is an open access article published by Thieme under the terms of the Creative Commons

Attribution- NonDerivative-NonCommercial-License,

permitting copying and reproduction so long as the original work is given appropriate credit. Contents

may not be used for commecial purposes, or adapted, remixed, transformed or built upon. (https:// creativecommons.org/licenses/by-nc-nd/4.0/)

Georg Thieme Verlag, Rüdigerstraße 14, 70469 Stuttgart, Germany

(ㄷ) (1) (ㅇ) $\ominus$ 